\title{
Educação Física na Educação Infantil: educando crianças ou meninos e meninas?*
}

\author{
Marina Mariano** \\ Helena Altmann***
}

\section{Resumo}

Este artigo trata das relações de gênero em aulas de Educação Física na Educação Infantil. A metodologia empregada na pesquisa que o originou consistiu na realização de observações de aulas e entrevistas com um professor e uma professora que lecionam em escolas públicas de um município da Região Metropolitana de Campinas, SP, Brasil. Expectativas e incentivos docentes, quando expressas para as crianças de forma polarizada, produziram desigualdades de gênero. Intervenções menos polarizadas produziram relações de gênero menos hierarquizadas $e$ desiguais entre as crianças, constituindo meninos e meninas como capazes de aprender e vivenciar o corpo e os gestos de forma ampla e diversificada.

Palavras-chave: Educação Física, Educação Infantil, Gênero.

* Recebido para publicação em 01 de novembro de 2013, aceito em 15 de novembro de 2015.

** Professora da Rede Municipal de Educação de Vinhedo, Vinhedo, São Paulo, Brasil.marina_mariano2002@yahoo.com.br

**** Professora da Faculdade de Educação Física e do Programa de PósGraduação em Educação da Universidade Estadual de Campinas, Campinas, SP, Brasil. altmann@fef.unicamp.br 
412 educando crianças ou meninos e meninas?

Physical Education in Early Childhood Education: Educating Children or Boys and Girls?

\begin{abstract}
The article deals with gender relations in Physical Education classes in Early Childhood Education. The methodology involves performing class observations and interviews with a male teacher and a female teacher, who teach at public schools in a municipality of the Metropolitan Region of Campinas, SP, Brazil. Expectations and teachers incentives, when expressed in a polarized manner, produce gender inequalities. Less polarized interventions produced less hierarchical and unequal gender relations, forming boys and girls as being capable of learning and experiencing the body and gestures in a broad and diversified way.
\end{abstract}

Key Words: Physical Education, Early Childhood Education, Gender. 
"Pular corda é coisa de menina." "Vamos jogar futebol, mas menina não pode." "Os meninos sempre ganham!" Tais afirmações proferidas por crianças, bem como seu questionamento, conduziram o desenvolvimento deste artigo que analisa as relações de gênero em aulas de Educação Física com crianças na Educação Infantil. Observações e vivências de uma das autoras deste artigo como professora de Educação Física nesse nível de ensino suscitaram indagações sobre as diferenciações de gênero nesse espaço, tais quais: Como são as relações entre crianças e professoras(es) nas aulas de Educação Física em uma escola de Educação Infantil? De que maneira as ações dessas(es) professoras(es) de Educação Física na escola interferem nas relações e constituição de diferenças de gênero desde a infância? Que construções de gênero são viabilizadas nesses espaços?

Brah (2006:14) afirma que "as desigualdades de gênero penetram em todas as esferas da vida". Pensando a escola e a Educação Física como duas dessas esferas, entendemos que seja importante analisar o contexto em que se dão essas situações $e$ pensar suas relações com algumas das teorias desenvolvidas por estudiosas(os) da área. Nas escolas infantis em que a Educação Física está presente, parte dessa responsabilidade também é do(a) docente que leciona essas aulas, já que toda aula é aqui entendida como uma forma de intervenção no constante processo de constituição dos sujeitos.

A presença da Educação Infantil na educação brasileira foi oficializada há cerca de 20 anos, quando a Constituição de 1988, juntamente com o Estatuto da Criança e do Adolescente (Brasil, 1990), passaram a garantir a Educação Infantil como um "direito das crianças, dever do Estado e opção da família" (Kramer, 1995:3).

A relação da Educação Física com a Educação Infantil, e sua produção de conhecimento voltada para esse nível, datam do século XIX no Brasil, quando encontramos estudos e debates sobre o papel da Educação Física (ainda chamada de Ginástica) em instituições educacionais para crianças de até seis anos (Khullmann 
Jr., 1991). Apesar de incentivada e ressaltada como uma prática importante ao longo dos anos devido aos benefícios que poderia trazer, como a ênfase no aspecto lúdico, no desenvolvimento de habilidades corporais ou o acesso a conhecimentos e práticas da cultura corporal de movimento, a Educação Física nas escolas de Educação Infantil no Brasil, enquanto área específica de conhecimento, nunca foi obrigatória. No entanto, diversas escolas particulares e públicas em alguns municípios brasileiros, como aquele em que foi desenvolvida esta pesquisa, contratam docentes de Educação Física para atuar na Educação Infantil. ${ }^{1}$

Gênero tem sido apontado como um importante marcador social de diferenças nas práticas pedagógicas de Educação Física escolar (Altmann, 2015; Clark, Paechter, 2007; Jacó, 2012; Thorne, 1993; Uchoga, 2012; Wenetz et al., 2006) e da Educação Infantil (Faria, 2006; Finco, 2008; Vianna; Finco, 2009). Neste artigo, ele é empregado para analisar relações estabelecidas em práticas de Educação Física no âmbito da Educação Infantil. $\mathrm{O}$ conceito de gênero foi desenvolvido para contestar a naturalização da diferença sexual em múltiplas arenas de luta, e ainda explicar $e$ transformar sistemas históricos de diferença sexual nos quais "homens" e "mulheres" são socialmente constituídos e posicionados em relações de hierarquia e antagonismo (Haraway, 2004).

As interpretações sociais são extremamente relevantes quando se fala em gênero. Ainda segundo Haraway (2004:11),

apesar de importantes diferenças, todos os significados modernos de gênero se enraízam na observação de Simone de Beauvoir de que "não se nasce mulher" e nas condições sociais do pós-guerra que possibilitaram a construção das mulheres como um coletivo histórico, sujeito-em-processo.

Sobre a relação da Educação Física com a Educação Infantil, vide os trabalhos de Deborah Sayão, em particular Sayão (1996). 
Embora já tivesse sido anteriormente utilizado por outros pensadores, como por Robert Stoller, a repercussão desse conceito nas Ciências Humanas está originalmente relacionada ao texto de Gayle Rubin (1975), "The traffic in women: notes on the political economy of sex".

\begin{abstract}
Suas reflexões contribuíram para a criação de um horizonte de transformação social no qual a diferença já não poderia ser compreendida como um ato casual da natureza, mas sim como uma ação de diferenciação em que a distinção é construída socialmente, impondo uma hierarquia do sexo $e$ da sexualidade através da divisão do trabalho, da família, do matrimônio e da reprodução (Mayorga, et. al., 2013:17).
\end{abstract}

O texto de Scott (1995) ", "Gênero: uma categoria útil de análise histórica" é um marco importante na utilização desse conceito no campo das Ciências Humanas e da Educação no Brasil. Nesse texto, gênero é conceituado como uma categoria analítica e relacional a qual se articula com raça, classe, geração, sexualidade, entre outras; também é pensado como uma forma de dar significado às relações de poder. Atualmente, além de um conceito, gênero constitui-se um campo de produção de conhecimento (Matos, 2008).

As análises desenvolvidas neste texto são baseadas em uma pesquisa de campo de inspiração etnográfica. Foram utilizadas ferramentas metodológicas que caracterizam a etnografia, tais quais: é interpretativa, microscópica, não profética, busca uma análise densa da descrição dos acontecimentos, gestos e atitudes do universo pesquisado, além de uma simultânea análise das próprias reações frente ao outro, definida como reflexividade (Geertz, 1989).

As análises resultam de um período de observação de aulas de dois docentes - um professor e uma professora - da área atuando com crianças em escolas de Educação Infantil. Na época

2 A primeira publicação em língua inglesa desse artigo é de 1988 e sua primeira tradução e publicação no Brasil ocorreu em 1990. 
da realização da pesquisa, o município contava com cinco professoras e um professor de Educação Física nesse nível de ensino. Considerando que uma das pesquisadoras é professora na mesma rede de ensino, o primeiro critério de seleção dos sujeitos da pesquisa foi não possuir relações pessoais com a pesquisadora. A compatibilidade dos horários de aulas com a disponibilidade para realização das observações por parte da pesquisadora e a escolha de um docente do sexo masculino e outra do feminino foram os outros critérios utilizados para definir as instituições onde a pesquisa seria realizada. Para manter o sigilo dos sujeitos, seus nomes, bem como os das escolas são fictícios.

Os dois Centros de Educação Infantil (CEI's) ${ }^{3}$ são geograficamente próximos um ao outro e atendem a crianças de um mesmo bairro da periferia da cidade, cujos moradores apresentam baixo nível socioeconômico. As observações foram realizadas durante oito meses a partir de abril de 2009, tendo sido concluídas em novembro do mesmo ano em uma das escolas e, na outra, em setembro, devido ao afastamento do cargo por parte da professora. As aulas de Educação Física nas escolas eram semanais, com duração de 45 minutos, totalizando assim 13 aulas observadas da Professora Beatriz e 17 do Professor César.

Também foram realizadas entrevistas semiestruturadas ${ }^{4}$ com os dois docentes, a fim de relacioná-las com suas práticas na rotina escolar. As entrevistas, realizadas na própria escola, tiveram duração aproximada de uma hora, tendo sido gravadas em áudio e posteriormente transcritas.

O Professor César atuava no CEI Pão de Mel, tendo se formado em uma universidade pública no ano de 2006. Desde então, trabalha em instituições de ensino de educação infantil $e$ ensino fundamental. A Professora Beatriz trabalhava no CEI

3 Essa é a nomenclatura adotada pelo município para esse tipo de instituição.

4 Esse tipo de entrevista toma como foco um assunto sobre o qual se confecciona um roteiro com perguntas principais que serve de eixo orientador, complementadas por outras questões que surgem a partir das respostas do informante. 
Algodão Doce e concluiu sua graduação em uma instituição privada no ano de 2002, tendo também tido experiências prévias no ensino fundamental. Ambos trabalham com educação infantil naquele município desde o início do ano letivo de 2007.

Assim, partindo de trechos de aulas e das entrevistas, este artigo analisa como situações de aula e intervenções docentes contribuem na construção das relações de gênero, $e$, em muitos momentos, classificam e hierarquizam os corpos e as práticas de meninos e meninas de modo distinto. São analisados práticas $e$ usos de linguagem que produzem desigualdades de gênero nessas aulas. Para efeitos deste artigo, restringimos as análises às situações ocorridas nas aulas que envolviam apenas as crianças da fase II (idade aproximada de cinco anos).

As aulas foram observadas por uma das pesquisadoras, que posicionava-se próxima ao grupo de alunos nos espaços de realização da aula, que compreendiam o pátio da escola, locais próximos a ele e, no CEI Algodão Doce, uma pequena quadra descoberta. Não foram realizadas intervenções pedagógicas por parte da pesquisadora; sua presença despertava curiosidade por parte das crianças que lhe questionavam sobre seus motivos $e$ sobre o que escrevia. Por vezes, para justificar sua presença naquele ambiente e simultaneamente transformá-la em uma estratégia de disciplinamento, tanto o professor quanto a professora usaram o argumento de que ela estaria ali para anotar o nome daqueles que "fizessem bagunça" durante a aula. Contudo, as crianças pareciam não acreditar muito nessa explicação, pois sempre voltavam a indagar a pesquisadora, tentando apreender o motivo daquela inserção escolar tão passiva $e$ incomum àquele ambiente.

\section{Relações de gênero em movimento}

A maneira de conduzir as aulas e trabalhar com os conteúdos de Educação Física era bastante distinta nas duas escolas, tendo repercussões também no que se refere às relações de gênero. No CEI Pão de Mel, as aulas costumavam seguir o 
mesmo roteiro: o professor chegava à sala, entrava e, sentado na roda de conversa com as crianças, cumprimentava-as e explicava o que seria feito durante o tempo em que permaneceriam juntos. Ele organizava sua aula propondo experiências corporais às crianças, utilizando-se de diferentes materiais $e$ incentivos, $e$ permitindo que elas mesmas escolhessem aquelas atividades que queriam praticar primeiro, propondo trocas, posteriormente. Ao se dirigirem ao espaço previamente combinado, não havia formação de filas. Todos caminhavam acompanhando o professor de forma aleatória. Durante o período em que foram feitas as observações, o professor nunca dividiu as turmas por sexo. Sempre que as brincadeiras exigiam uma separação em grupos distintos, eles eram mistos. Uma organização menos formal possibilitava que as crianças se agrupassem de maneiras variadas, realizando suas próprias escolhas e vivenciando relações que não eram marcadas pela separação por sexo. Grupos de meninas e meninos, só de meninos ou de só de meninas formavam-se e dissolviam-se durante as aulas, sem que essa distinção despontasse como um elemento organizador da aula e dos conteúdos trabalhados.

Cabe destacar que essa organização adotada pelo professor propiciava relações de gênero não polarizadas, caracterizadas por uma maior interação entre meninos e meninas quando comparadas a situações em que as crianças brincavam livremente dentro das aulas, sem nenhuma intervenção docente. Nesses momentos mais livres, embora todos tivessem as mesmas oportunidades, havia um interesse predominante, embora não exclusivo, das meninas pelas atividades menos dinâmicas, como jogos de encaixar, manipulação de pequenos brinquedos, brincadeiras de roda e de palmas. Por outro lado, a maioria dos meninos ficava envolvida naquelas atividades que necessitam de mais movimentos e um maior espaço para acontecer, como as corridas e jogos com bolas. Os grupos que se formavam eram um tanto quanto "generificados", ou seja, refletiam concepções dominantes de masculinidade e feminilidade (Messner, 1992).

Outra característica que merece ser ressaltada é que, nesses momentos de separação, as atividades feitas pelas meninas 
aparentemente requeriam maior organização, ao contrário das escolhidas pelos meninos. Enquanto elas organizavam filas para pular corda, formavam pequenos grupos, estabeleciam regras para ver a ordem de quem começava a brincadeira ou usavam marcações no chão para delimitar espaços, os meninos pareciam não se importar com a disposição do grupo ou sua organização espacial. Eles transmitiam a impressão de que tudo era válido: brincavam no espaço que tivesse, como quisessem, entrando $e$ saindo da brincadeira quando bem entendessem.

Outro aspecto a ser considerado refere-se à linguagem adotada pelo professor. Quando falava com as crianças, tanto para explicar as atividades, quanto para resolver qualquer outro tipo de situação durante a aula, como desentendimentos, o professor constantemente usava o termo "criança(s)". Se a linguagem por ele utilizada não determinava uma separação de gênero, o mesmo pode ser dito em relação à maneira como organizava as crianças. A forma como planejava as aulas oferecialhes autonomia e liberdade frente às escolhas e à organização do grupo para as atividades. A partir disso e nessas situações, observamos que as escolhas, relações e práticas construídas pelas crianças não traziam marcas de separação entre meninos $e$ meninas.

Também existia uma sequência de ações que caracterizava as aulas da Professora Beatriz, do CEI Algodão Doce. Tal qual ocorria com o outro professor, ao chegar à porta da sala, a Professora Beatriz sempre era recebida com alegria e entusiasmo pelas crianças. A seguir, elas rapidamente se aglomeravam a sua frente, formando um grande "bando". Diante do alvoroço, a professora solicitava a formação das filas para que pudessem seguir em frente e iniciar a aula. Sem novas instruções, as crianças já sabiam como agir: duas filas se formavam, uma só com os meninos e outra só com as meninas. Nessa formação, todos seguiam para o espaço da aula.

A mesma formação de filas era utilizada em outros momentos escolares e com outras professoras, como para deslocamentos até o refeitório. Também durante as aulas de 
Educação Física, foram frequentes as separações em grupos de meninos e meninas, tanto nas atividades em duplas, quanto em grupos maiores.

Assim, a pesquisa desenvolvida constata que em ambas as escolas a organização escolar $e$ as ações docentes interferiam no comportamento das crianças. Ao solicitar a divisão da turma em duas, as crianças já se posicionavam da maneira como se costumava trabalhar naquele ambiente: no CEI Algodão Doce, meninos e meninas posicionavam-se separadamente, enquanto na CEI Pão de Mel, formavam-se dois grupos mistos.

Ao pesquisar as relações de gênero entre adulto e crianças $e$ entre as próprias crianças em uma escola municipal de Educação Infantil paulistana, Finco (2008) diz que as filas, apesar de serem justificadas pelas professoras como facilitadoras na hora de organizar e locomover o grupo, são também uma forma de mostrar os meninos, que são estigmatizados como agitados, bagunceiros $e$ aqueles que não prestam atenção, contrastando com o bom exemplo dado pelas meninas na organização. A mesma autora ainda completa que a prática educativa de separar as

"filas de meninas" e "filas de meninos", realizadas repetidas vezes e cotidianamente, vai confinando os comportamentos das meninas para que sejam mais responsáveis, dedicadas, comunicativas, estudiosas, interessadas e sensíveis (Finco, 2008:3).

Pereira (2004) indagou as professoras das turmas por ela estudadas sobre as filas separadas para meninos $e$ meninas $e$ concluiu, em análise das respostas, que

as professoras trabalham dividindo alunos(as) por sexo principalmente para minimizar os problemas que surgem durante o convívio entre meninos e meninas, e as crianças acabam por reproduzir este comportamento durante suas interações com os colegas (Pereira, 2004:70). 
No CEI Algodão Doce, quando perdiam o interesse $e$ deixavam a atividade, a professora Beatriz solicitava que as crianças a retomassem, sempre as lembrando de onde deveriam permanecer durante o tempo da aula. Foi possível perceber que, geralmente, ao deixar a brincadeira proposta, a primeira ação das meninas era de sentar em um canto, o que rapidamente atraía mais algumas delas para alguma conversa ou brincadeira no tanque de areia. A frequência com que os meninos saíam da aula foi menor que a das meninas, porém, quando isso acontecia, alguns também se sentavam para observar ou brincavam de corrida. A professora intervinha diante dessas desistências, buscando reinseri-los(as) na situação de ensino proposto.

Fora as saídas repentinas da atividade proposta, que eram logo impedidas, as crianças acatavam as instruções da professora, também no que se refere à organização polarizada de meninos $e$ meninas no espaço e não expressavam resistência ou contrariedade diante de suas falas. As crianças interagiam entre si sem uma separação por gênero nos momentos de conversa $e$ brincadeiras entre as atividades, mas aceitavam sem estranhamento a divisão imposta nas práticas dirigidas. Esse grupo de crianças vinha tendo aulas com a professora Beatriz ao longo dos dois últimos anos, de modo que sua forma de organizá-las e conduzi-las já tinha sido assimilada pelo grupo. Separações semelhantes faziam parte da cultura escolar, que dessa forma organizava filas, idas ao banheiro entre outros. Segregações de gênero foram produzidas, assimiladas e naturalizadas naquela instituição, por aquelas crianças.

No CEI Pão de Mel, também existia dispersão, mas em menor proporção, o que está ligado a aspectos diversos. O primeiro deles é que, em sua maioria, as turmas do CEI Algodão Doce eram mais numerosas do que no CEI Pão de Mel - sendo em torno de 25 crianças por sala naquela e 15 nesta última -, o que tinha implicações significativas no trabalho docente, dentre outras, no que diz respeito ao controle das turmas e à condução das práticas. Outro aspecto é a forma como o professor desenvolvia sua aula. Por expor suas ideias às crianças ainda 
dentro da sala, ao chegar ao espaço combinado, elas já sabiam o que iria acontecer $e$, aos poucos, se organizavam para as atividades. Não havia tantas exigências de comportamentos e atitudes específicos, de modo que diferentes formas de participação das crianças diante do proposto não eram vistas como ausência de participação ou como atuação inadequada. As aulas nessa escola tinham um caráter mais exploratório, de modo que a própria organização da aula contribuía para a não configuração de "problemas de comportamento" entre as crianças. Ao professor propor atividades desprovidas de expectativas de movimento, ações e comportamentos muito precisas $e$ delimitadas, as crianças tinham margens amplas para agir e fazer escolhas, sem que suas ações e comportamentos logo se configurassem como erros, deficiências, problemas. A esse contexto de aula, adicionam-se intervenções docentes que, ao longo do período de observação desta pesquisa, incentivavam igualmente meninos e meninas para as práticas. Esse conjunto de aspectos constituía as aulas de Educação Física em momentos em que crianças brincavam e agiam juntas, sem ter seus corpos $e$ ações demarcados por diferenças de gênero.

Evitar a segregação entre meninos e meninas durante seu crescimento até a vida adulta talvez seja também uma questão de oportunidades. Nesta pesquisa, quando havia efetiva liberdade de escolha, seja dentro da aula, seja na escola como um todo, a formação de filas diferenciadas por sexo não era a opção preferida pelas crianças. É possível afirmar que a separação entre meninas e meninos não era algo constante e tampouco "natural". Sua separação ou a interação mais aleatória entre as crianças estava relacionada à organização e à intervenção escolar e docente diante dessas questões, às formas e à linguagem com a qual se dirigia às crianças. Esse argumento será retomado no item seguinte deste artigo. 


\section{Confiança e dúvida sob uma perspectiva de gênero}

No CEI Pão de Mel, as atividades competitivas não eram frequentes, mas quando realizadas, as equipes eram mistas. Meninos e meninas geralmente decidiam a divisão de grupos aleatoriamente: quando solicitado pelo professor, as crianças se dirigiam aos espaços determinados de acordo com a proximidade que estavam do local ou acompanhavam um colega com quem tivessem afinidade.

De modo distinto, no CEI Algodão Doce, durante o período de observações, predominaram brincadeiras cuja ideia central era a competição entre dois times opostos, lembrando a estrutura de jogos esportivos. O sexo era o critério usado para a divisão das crianças, de modo que meninos e meninas competiam entre si. Para organizar os times, geralmente a professora dava às crianças comandos semelhantes, que vinham acompanhados de gestos indicando a posição a ser ocupada: "Meninas do lado de cá e meninos do lado de lá" ou "Eu quero todas as meninas aqui e todos os meninos ali".

Destacamos aqui, uma sequência de falas da professora ${ }^{5}$ durante um jogo de queimada, de caráter competitivo, em que foram colocados meninos e meninas em times separados, competindo um contra o outro. Logo no início, várias meninas foram queimadas rapidamente e a professora comentou: "Vocês têm que tentar pegar a bola, vocês estão bobeando e os meninos estão ganhando!". E, em seguida, se dirige aos meninos: "Vamos, vocês estão ganhando!".

No time das meninas, algumas se distraíram e começaram a conversar. Logo, a professora interveio: "Meninas, se vocês ficarem aí só conversando, os meninos vão ganhar! Que fofoqueiras!". E mais uma vez reforçou aos meninos: "Queima elas! Vocês vão ganhar!". E para as meninas: "Será que vocês conseguem queimar alguém?". Os meninos ganharam o jogo e a

5 Anotações feitas no diário de campo em 19/05/2009. Grifo nosso. 
professora encerrou a atividade: "E os meninos ganharam! Eles foram muito espertos! E as meninas, coitadinhas, bobearam!".

As expressões, que aparentemente soam como formas de incentivo, expressam desigualdades significativas. Ainda que postos na mesma situação, as expectativas em torno do resultado das ações para um grupo e outro são diferentes. Ao perguntar para a classe se as meninas conseguem queimar alguém durante o jogo de queimada, fica evidente a existência da dúvida frente à sua capacidade para tal. Uma pergunta desse tipo voltada aos meninos soaria redundante, já que eles são tidos como "espertos e fortes" (expressões usadas pela professora Beatriz para caracterizálos). De acordo com Faria e Nobre (2003), atitudes como essas podem influenciar o bom desempenho deles e o fracasso delas diante de situações de aprendizagem, uma vez que interferem no comportamento de meninos e meninas, inibindo a expressão de diferentes manifestações corporais e atitudinais na infância. Assim sendo, afirmam as autoras, as formas como meninas e meninos vão sendo educados, influencia sua formação de tal maneira que pode contribuir para se tornarem mais críticos e esclarecidos ou para limitar suas iniciativas e aspirações. Também em relação às práticas corporais, as falas e formas de intervenção docentes podem torná-los mais ou menos confiantes em relação a suas habilidades e possibilidades de experimentar o corpo, logo, mais ou menos hábeis corporalmente.

Além da confiança no sucesso, força era outra característica atribuída aos meninos. Parece ocorrer aqui uma transferência de uma diferença na vida adulta à infância, desconsiderando o fato de que, nessa faixa etária, diferenças de força, estatura, velocidade etc. entre os sexos são pouco significativas. ${ }^{6}$ Em um jogo de pegagelo, foi combinado que, inicialmente, o time dos meninos correria atrás das meninas, "congelando-as" com o toque, e

6 Outro fato a considerar é que, mesmo entre adultos, a suposta maior força masculina não pode ser generalizada e pode ser pensada como historicamente construída. Sobre as diferentes fases do desenvolvimento infantil em uma perspectiva do desenvolvimento motor, vide Gallahue e Ozmun, 2005. 
posteriormente a situação se inverteria. Antes de começar a brincadeira, a professora Beatriz reforçou para os meninos que eles deviam apenas encostar a mão nas meninas e não empurrar nem puxar. Quando foi a vez das meninas pegarem, elas foram lembradas que "tem que correr muito rápido, o mais rápido que conseguir para tentar pegar os meninos". ${ }^{7}$

É perceptível que a dúvida na capacidade delas em alcançar o objetivo da atividade persiste em diferentes momentos $e$ brincadeiras, sendo simultânea a confiança em relação aos meninos.

No que se refere a possíveis diferenças de interesse em reação às aulas, a professora manifestou-se da seguinte forma:

Eu acho que os meninos são mais interessados. As meninas não tanto. As meninas eu acho que elas são mais... Elas conversam demais. Então elas gostam de ficar falando $e$ falando, nem que seja para contar o que o fulano está fazendo de errado, do que vivenciar mesmo a brincadeira que a gente está fazendo. Elas ficam meio receosas assim de estar fazendo. Isso não é geral, logicamente. Porque tem aquelas meninas que fazem de tudo, querem ser as primeiras. O que é mais comum é as meninas não se interessarem tanto e ficarem meio receosas dependendo da atividade. (...) Eu acho os meninos muito mais interessados do que elas. Acho que até os meninos muito mais criativos do que as próprias meninas. Mas as que têm interesse acho que são mais criativas do que os meninos. As que se predispõem a fazer são mais espertas, elas pegam as coisas mais rápido, as manhas da brincadeira, as regras da brincadeira, elas seguem e já conseguem pensar: olha, mas $e$ se fosse desse jeito... As que são interessadas se sobressaem aos meninos, mas a maior parte dos meninos é mais interessada e se dedica mais. ${ }^{8}$

7 Fala da professora, grifos nossos.

8 Trecho da entrevista realizada em 01/09/2009. 
Foi possível perceber pela fala da professora que, apesar do modo negativo como são vistas em diferentes situações ao longo da entrevista e das aulas, ainda existe uma expectativa positiva frente às meninas, não obstante, essa só é atingida mediante um interesse por parte delas. É a partir desse interesse que elas "conseguem pensar" e "seguir as regras", sobressaindo-se aos meninos, como expresso na fala acima.

Olhando pelas lentes de uma perspectiva cultural e dos estudos de gênero, não seria esse receio, essa falta de interesse das meninas apontada por Beatriz também produto da dúvida comumente apresentada pela sociedade frente à capacidade delas de obterem os mesmos bons resultados atingidos pelos meninos nas práticas corporais? A dúvida sobre sua capacidade de realizar algo com o corpo não seria "incorporada" por elas? Essa percepção de incapacidade não teria como efeito uma menor aprendizagem e consequente maior incapacidade? Tal qual afirma Kohan (2003:73), "o que um sujeito é não está dissociado da experiência de si mesmo que é induzido a ter numa instituição como a escola".

Também chama a atenção na fala da professora sua interpretação de que, ao se dedicar, se interessar, a menina sobrepõe-se ao menino ao ponto de superá-lo. No entanto, ao considerar essa situação uma exceção, a regra da incapacidade e ineficiência das meninas diante das práticas corporais não é colocada em questão, mantendo-se a visão estereotipada de meninos serem mais habilidosos que meninas. Essa percepção também está presente em outros níveis de ensino (Altmann et al., 2011). Além disso, em muitos casos, principalmente com crianças maiores e jovens, ocorre da eficiência corporal das meninas ser interpretada como algo que foge ao universo feminino, tornandoas sujeitas a serem vistas como não femininas (Goellner, 2005, Altmann, 2015).

Nas aulas do CEI Pão de Mel, talvez pelo fato de serem grupos mistos, não houve momentos em que meninos e meninas foram incentivados de maneira desigual ou em que as expectativas em torno do resultado de suas ações divergissem. 
Eram comumente usadas, tanto para meninos quanto para meninas, palavras e expressões de incentivo, tais quais: "Vamos! Acerta ela"! (ou ele), ou "Muito bom, Camila! Na próxima dá para jogar um pouco mais longe".

$\mathrm{Na}$ entrevista, quando é perguntada ao professor sua opinião a respeito da existência ou não de diferentes habilidades entre meninos e meninas, assim como foi feito com a outra docente que participou desta pesquisa, registramos a seguinte resposta:

Eu acho que agora, eu diria que não. Não tem [diferença de habilidade entre meninos e meninas]. Pela idade. Porque eles estão brincando de tudo ainda. Eu acho que isso vai acontecer mais lá para frente. Acho que passa aí pela primeira fase do fundamental e na $5^{\mathrm{a}}$ série já acontece, porque daí, elas param de brincar de umas coisas e eles também param de brincar de outras, mas por enquanto... Aqui a gente não trabalha com esporte. Não tem então essa coisa do esporte. As brincadeiras, todos eles brincam de tudo. Então, eu não percebo diferença. Tem diferença da experiência da criança, que não depende do sexo. ${ }^{9}$

Os dados desta pesquisa indicam que, não percebendo diferenças de habilidade entre meninas e meninos, o professor não as reforçava. Em outras palavras, não era possível reforçar algo que, na percepção desse professor, não existia.

De forma distinta, na outra escola, as ações pedagógicas e correções docentes eram marcadas por desigualdades de gênero. Durante uma brincadeira chamada "limpando a casa" ${ }^{10}$, meninos foram posicionados de um lado da rede de vôlei e meninas do outro. O objetivo da brincadeira era jogar bolinhas de meia, que simulavam a sujeira, por cima da rede para, no final, ver qual grupo havia ficado com a casa mais limpa. Antes de dar início à atividade, a professora explicou à classe como era o jogo $e$

9 Trecho da entrevista realizada em 10/09/2009.

${ }^{10}$ Anotações feitas no diário de campo em 16/06/2009. 
comentou: "Vamos ver quem fica com a casa mais limpinha! Eu sei que as meninas são craques de limpar a casa!"

Em outra atividade realizada no mesmo dia, com a mesma divisão de grupos, as crianças foram posicionadas em filas, cada qual do seu lado da rede. A intenção era que a primeira criança da fila jogasse a bola por cima da rede para a primeira criança da fila do outro lado. No decorrer da brincadeira, o time das meninas perdeu o interesse e se distraiu. Algumas se juntaram e passaram a conversar em pequenos grupos, outras apenas observavam o ambiente. Diante da situação, a professora alertou: "Vamos! Vou ter que trazer um despertador para as meninas!".

A dificuldade em fazer com que a bola chegasse à mão da pessoa do outro lado da quadra era partilhada por muitas crianças. Muitas vezes, a bola era arremessada sem direção precisa, não ultrapassando a rede ou indo longe demais, fosse para o fundo ou para a lateral da quadra. Tal dificuldade de precisão era comum a meninos e meninas. Novamente, observouse que as correções docentes eram marcadas pelo gênero. Alguns meninos lançaram a bola além do espaço pretendido e a professora solicitou-lhes que a jogassem mais perto: "Vocês estão muito fortes!". Minutos depois, uma menina errou o arremesso e a professora, em tom de brincadeira, aproximando-se dela e segurando sua mão, disse: "Sua mão está torta! Vem aqui que eu vou consertar!".

As críticas às meninas eram associadas ao gênero feminino, como ao ressaltar sua falta de velocidade pela necessidade do uso de um "despertador", ou pelo alerta da necessidade de correr muito rápido em uma brincadeira para tentar pegar algum colega, alerta esse não feito aos meninos. Incentivos positivos só foram feitos quando a brincadeira remetia a uma função social tipicamente feminina como as tarefas domésticas. No jogo "limpando a casa", a fala da professora indicava seu possível sucesso. Nesse caso, apesar de não serem consideradas tão "espertas e fortes" quanto os meninos, a possibilidade de melhor desempenho delas estava colocada, já que fariam algo supostamente próprio de seu universo doméstico. 
As estratégias educativas adotadas acabavam marcando a atuação das meninas de forma negativa, com críticas associadas ao gênero feminino. Suas atuações eram colocadas em dúvida ao invés de afirmadas por aquilo que eram capazes de executar. De modo semelhante, ainda que em outro nível de ensino, Fontana (2001) retoma em um artigo sua experiência com a Educação Física na escola descrevendo o quanto seu corpo era marcado pela negatividade, tendo como efeito o definhamento do seu desejo de aprender e o seu distanciamento da Educação Física e de seus conteúdos.

Outro momento em que diferenças de gênero perpassaram o olhar e a intervenção docentes refere-se a uma atividade de escalada, na qual a professora amarrou duas cordas em uma cerca no alto de um barranco para que as crianças subissem com o apoio daquelas. Para que isso fosse feito, a professora solicitou à turma que se dividissem em dois grupos. Ela chamou alguns nomes e pediu que fossem para uma determinada corda, enquanto as outras crianças que não foram chamadas deveriam formar uma fila diante da outra corda. Não era uma atividade competitiva, e sim de vivência. O objetivo, conforme ressaltado por ela, era o de "chegar lá em cima, usando a corda para subir, $e$ não colocando a mão no chão" como faziam algumas crianças. ${ }^{11}$ Uma das filas era formada por meninos e meninas e a outra, somente por meninos, em ambas as turmas com as quais foi feita a atividade. Não ficaram evidentes nessa aula, situações que separassem ou diferenciassem meninos de meninas.

No entanto, a professora interpretou a situação de outra forma, novamente marcando a atuação das meninas pela dificuldade, conforme manifestou durante a entrevista em que descreveu esse momento da aula para sustentar seu argumento:

Professora Beatriz: (...) foi uma atividade de escalada que tinha um lado mais difícil, um lado mais fácil, e todo mundo tinha que brincar e subiam dois por vez. Como eles iam ter

\footnotetext{
${ }^{11}$ Anotações feitas no diário de campo em 01/09/2009.
} 
que ficar um tempo ali, esperando para chegar a vez deles, eu coloquei as meninas primeiro para fazerem o mais fácil para passarem depois pelo mais difícil, porque dava para dar atenção para os dois ao mesmo tempo porque eu tinha certeza que os meninos iriam dar um jeito de se sair melhor na corda que estava para subir mais difícil. Você tenta fazer mais ou menos essa diferenciação.

Pesquisadora: Mas tinham meninos também na fila das meninas...

Professora Beatriz: É. Aqueles que geralmente têm mais dificuldades. ${ }^{12}$

O critério usado pela professora para a formação de um grupo, no qual meninos ficaram com meninas, foi definido por ela como sendo sua menor habilidade. A possibilidade de meninas mais habilidosas comporem o outro grupo não foi cogitada. Além disso, não foi oportunizado aos tidos como "menos habilidosos" a experiência de subir na corda no lado mais íngreme, reforçando e produzindo desigualdades entre as crianças, também no que se refere às aprendizagens do movimento. Ao oferecer oportunidades distintas, cada criança se desenvolve e experimenta o corpo de forma distinta, favorecendo a proliferação da ideia de uma "naturalização cultural" de diferenças de gênero. Nesse episódio e no seu relato, habilidade e gênero são categorias que se sobrepõem, perpassando as propostas didáticas, a organização da aula, as relações entre os sujeitos e suas experiências durante as aulas de Educação Física. Além disso, outras inúmeras dimensões do ensino das práticas corporais são recorrentemente preteridas em detrimento do desempenho. ${ }^{13}$

\footnotetext{
12 Trecho da entrevista realizada em 01/09/2009.

${ }^{13}$ A produção de conhecimento em Educação Física já fez inúmeras críticas ao chamado "paradigma da aptidão física e esportivo", construindo propostas pedagógicas que propiciam uma abordagem mais ampla dos seus conteúdos (esportes, dança, lutas, jogos e brincadeira e ginástica), chamados de cultura corporal ou cultura corporal de movimento (Bracht, 1999). Considerando as especificidades da infância, tais propostas também têm sido utilizadas na Educação Infantil, como em Ayoub (2005) e Sayão (1996).
} 
Embora no CEI Pão de Mel situações de conflito entre meninos e meninas não tenham sido observadas, o Professor César relatou dificuldades nesse sentido ao trabalhar com conteúdos envolvendo bolas, o que foi manifesto ao ser questionado na entrevista sobre os desafios enfrentados no dia-adia de trabalho:

Com as crianças, tem uma coisa que eu acho que é difícil. Agora nesse meu terceiro ano, estão acontecendo umas atividades com bola, chega perto de futebol, mas não é futebol. Aparece o preconceito de que é jogo para menino, daí você senta, conversa... Tem umas meninas que jogam tudo que você propõe, elas jogam de tudo. Tem uma menina da tarde, que ela só tem irmão, fica na rua o dia todo, cai, levanta, brinca de lutinha com os meninos, faz tudo. E aí, tinha uma vez que não queriam deixá-la jogar porque ela era menina. Daí senta, conversa. Depois todo mundo queria ser do time dela, porque ela é muito boa mesmo, é incrível. Então, é legal. ${ }^{14}$

Nesse caso, a semelhança da atividade proposta com o futebol explica, segundo o professor, os conflitos de gênero enfrentados por ele na escola. Embora o número de meninas que pratiquem essa modalidade esportiva seja hoje crescente $e$ significante, ela ainda é um esporte mais praticado por meninos. Os campeonatos de futebol amplamente transmitidos pela mídia televisiva são na sua maioria masculinos. Pesquisas apontam dificuldades no ensino nesse conteúdo com grupos mistos (Clark e Paechter, 2007; Uchoga, 2012; Viana, 2012).

A fala do professor também mostra que a socialização de uma menina com meninos, mediada pelo seu irmão, qualifica seus gestos e movimentos corporais. Esse trecho aponta uma reflexão do professor que segue na direção contrária àquela proposta por ele em suas aulas. Aqui, ele deixa transparecer que a condição de uma menina ser "boa" e "incrível" na prática do futebol só é

\footnotetext{
${ }^{14}$ Trecho da entrevista realizada em 10/09/2009.
} 
possível por ela pertencer a um universo em que a figura masculina está presente e exercendo influência direta para o desenvolvimento dessa capacidade.

Curiosamente, também é um trecho da entrevista com a professora Beatriz que fornece indícios que rompem com a lógica de aulas segregadas, protagonizado por ela quando aluna. Ao recordar seu tempo de escola, escolhe destacar um episódio marcante da época, que impactou sua formação. Embora ela faça uma crítica à experiência vivida, sua prática docente, tal qual observada durante esta pesquisa, não rompe com as segregações de gênero já vividas por ela enquanto aluna. ${ }^{15}$ Segue o trecho do relato:

...eu sempre gostei das aulas de EF... tanto é que eu brigava muito com um professor. Para mim é uma coisa que era muito marcante porque o professor não deixava que as meninas jogassem futebol e eu achava o cúmulo! Como a gente não podia jogar futebol? Então ia lá, tinha-se um tempo, a gente marcava o tempo dos meninos e o tempo das meninas. Ou era o vôlei. Quando a rede estava montada a gente jogava vôlei, quando não estava montada a gente jogava futebol, só essas duas coisas. Nem o basquete não rolava. E então era assim, quando os meninos estavam jogando, eu ficava apitando o jogo, porque eu queria jogar e não podia e era assim que eu participava do jogo. Aí, fui lá e conversei com o professor, conversei, conversei e depois de muito custo, ele achava que era muito perigoso, mas depois de muito custo ele disse "está bom, mas desde que vocês arrumem uma autorização". Então ele falou para mim que se arrumasse, se todas as meninas tivessem autorização dos pais, ele liberaria.

\footnotetext{
${ }^{15}$ Embora esse ponto esteja além dos limites deste artigo, ele evidencia a importância da formação docente de modo a reelaborar e reconstruir práticas pedagógicas a partir daquelas vividas quando discente. Dimensões de gênero $e$ sexualidade, entre outras, precisariam ser levadas em conta.
} 
Aí eu fui lá, peguei, minha mãe assinou, eu trouxe para ele e ele disse: está bom, agora você senta aí e espera. Quando faltava acho que uns 10 minutos para acabar a aula, daí ele me deixou entrar para jogar. Isso foi uma coisa que me marcou muito.

Mas não era aquela aula dos sonhos, sabe? Eu chegava lá, ele dava aquela bolinha, tempo das meninas, tempo dos meninos, divide os times... Os meninos até podiam completar o time das meninas, mas as meninas, jamais podiam completar o time dos meninos. ${ }^{16}$

\section{Considerações finais}

Nesta pesquisa, foi possível observar que as atuações docentes influenciavam o comportamento, as ações $e$ a organização das crianças. As análises desenvolvidas possibilitam afirmar que a organização das crianças dentro das aulas de Educação Física variava de acordo com características da escola e da intervenção docente. Em ambas, ocorria de meninos e meninas se separarem em determinadas situações, como para algumas conversas ou para práticas socialmente reconhecidas como deles ou delas - como o futebol e jogos cantados com palmas. No entanto, na escola em que a distribuição das crianças era mais espontânea e livre, sem divisões rígidas marcadas pelo sexo, as crianças formavam grupos durante as atividades de aula de Educação Física em que essa marcação de diferenças não era uma constante, mas uma possibilidade. De modo distinto, na outra escola, grupos polarizados entre meninas e meninos eram formados pela professora ou, espontaneamente, pelas próprias crianças que pareciam ter incorporado essa divisão de mundo na sua organização social. Além disso, nessa instituição, diferenças entre eles e elas eram marcadas - e, ao que tudo indica, produzidas - pela linguagem docente e pelas atividades propostas durante as aulas. Meninas eram recorrentemente vistas como menos capazes para as práticas corporais do que meninos e essa

\footnotetext{
${ }^{16}$ Trecho da entrevista realizada em 01/09/2009.
} 
percepção contribuía na produção dessa mesma diferença. $\mathrm{Na}$ outra escola, tais diferenças não eram percebidas - com exceção de atividades próximas ao futebol - $e$ tampouco eram reforçadas durante as aulas.

As expectativas docentes e os incentivos oferecidos em torno de um gênero e de outro eram expressas por falas e gestos. Emoções como decepção ou alegria eram demonstradas de acordo com os resultados das ações das crianças nas aulas, que eram avaliadas de acordo com um padrão de movimento $e$ comportamento pré-estabelecido. As atuações dos meninos eram vistas como estando mais próximas desse padrão de excelência, enquanto as das meninas estariam aquém do esperado, sendo corrigidas e educadas pela marcação da falta, do erro ou da ineficiência e não de estímulos positivos em relação às suas habilidades já adquiridas e potencialidades.

Por outro lado, a pesquisa também identificou uma atuação docente que buscava incentivar positivamente todas as crianças da turma, independentemente dos acertos ou erros cometidos. Nesse contexto, as atividades propostas eram menos dirigidas $e$ tampouco continham uma expectativa rígida do que seria o sucesso. A menor interferência na dinâmica das aulas possibilitava que as próprias crianças construíssem as relações entre elas, sem impor distinções e polarizações de gênero também no que se refere aos conhecimentos da Educação Física. Desse modo, a partir dos dados obtidos nesta pesquisa, conclui-se que intervenções menos diretivas durante as aulas de Educação Física produziram relações de gênero menos hierarquizadas e menos desiguais, garantindo espaço e oportunidade para que as próprias crianças rompessem com fronteiras de gênero socialmente estabelecidas.

Assim, embora houvesse nas duas escolas, durante as aulas de Educação Física, separações entre meninas e meninos, em uma delas a separação era constante e organizada pela professora $e$ pelas crianças, enquanto na outra, era eventual e organizada pelas crianças. Nesta última, essa separação nunca foi uma iniciativa 
docente, embora, diante dela, o professor também não interviesse no sentido de eliminá-la.

Por fim, conclui-se que aulas de Educação Física na Educação Infantil podem tanto acomodar, quanto desafiar regimes de verdade sobre gênero, as crianças e suas relações com as práticas corporais, percebendo e constituindo meninos e meninas como capazes de aprender e vivenciar o corpo e os gestos de forma ampla e diversificada.

\section{Referências bibliográficas}

Altmann, Helena. Educação física escolar: relações de gênero em jogo. São Paulo, Cortez, 2015.

AltmANN, Helena et al. Educação física escolar e igualdade de gênero: um estudo transcultural. Relatório de Pesquisa. Brasil - Espanha. Campinas, Unicamp, 2011.

Altmann, Helena; Ayoub, Eliana; AmARAl, Silvia C. F. Gênero na prática docente em educação física: "meninas não gostam de suar, meninos são habilidosos ao jogar"? Revista Estudos Feministas vol.19, n², Florianópolis, UFSC, 2011, pp.491-501 [<http://www.scielo.br/scielo.php?script=sci arttext\&pid=S0104026X2011000200012\&lng =pt\&nrm =iso $>$ - acesso em: dez. 2015]

AYOUB, Eliana. Narrando experiências com a Educação física na Educação Infantil. Revista Brasileira de Ciências do Esporte vol. 26, n³, Campinas, 2005, pp.143-158.

BRACHT, Valter. A constituição das teorias pedagógicas da educação física. Cadernos Cedes Ano XIX, nº 48, ago. 1999, pp.69-88.

BRAH, Avtar. Diferença, diversidade, diferenciação. Cadernos Pagu (26), Campinas, Núcleo de Estudos de Gênero-Pagu/Unicamp, jan/jun. 2006, pp.329-365.

BRASIL. Estatuto da criança e do adolescente. São Paulo, Cortez, 1990.

ClARK, Sheryl e PAECHTER, Carrie. "Why can't girls play football?" Gender dynamics and the playground. Sport, Education and Society vol. 12, n 3, ago. 2007, pp.261-276. 
FARIA, Ana Lúcia G. de. Pequena infância, educação e gênero: subsídios para um estado da arte. Cadernos Pagu (26), Campinas, Núcleo de Estudos de Gênero-Pagu/Unicamp, jan/jun. 2006, pp. 279-287.

FARIA, Nalu; NOBRE, Miriam. O que é ser mulher? O que é ser homem? Subsídios para uma discussão das relações de gênero. In: COORDENADORIA especial da mulher (org.). Gênero e educação: caderno para professores. São Paulo, Secretaria Municipal de Educação, 2003, pp. 29-42.

FINCO, Daniela. Socialização de Gênero na Educação Infantil. In: Fazendo Gênero 8: Corpo, violência e poder, 2008, Florianópolis. Anais. 2008 [<www1.fapa.com.br/cienciaseletras/pdf/revista43/artigo18.pdf $>\quad-$ acesso em: mai. 2009].

FONTANA, Roseli Cação. O corpo aprendiz. In: CARVALHO, Y. M. de; RubiO, K. (Org.). Educação Física e Ciências Humanas. São Paulo, Huicitec, 2001. pp. 41-52.

Gallahue, David. L.; OzMun, John. C. Desenvolvimento motor: um modelo teórico. Compreendendo o desenvolvimento motor: bebes, crianças, adolescentes e adultos. 3 ed. São Paulo, Phorte, 2005.

GEERTZ, Clifford. A Interpretação das culturas. Rio de Janeiro, Koogan, 1989.

GOELLNER, Silvana. Mulheres e futebol no Brasil: entre sombras e visibilidades. Revista Brasileira de Educação Física e Esporte vol. 19, $\mathrm{n}^{\circ}$ 2, São Paulo, ab./jun., 2005, pp.143-151.

HARAWAY, Donna. Gênero para um dicionário marxista: a política sexual de uma palavra. Cadernos Pagu (22), Campinas, Núcleo de Estudos de Gênero-Pagu/Unicamp, jan-jun. 2004, pp.201-246.

JACÓ, Juliana Fagundes. Educação Física escolar e gênero: diferentes maneiras de participar da aula. Dissertação (Mestrado) - Programa de Pós-Graduação em Educação Física, Unicamp, Campinas, 2012.

KOHAN, Walter. Infância entre a educação e a filosofia. Belo Horizonte, Autêntica, 2003.

KRAMER, Sonia. A política do pré-escolar no Brasil: a arte do disfarce. 5. ed. São Paulo, Cortez, 1995. 
KUHLMANN JR., Moysés. Instituições pré-escolares assistencialistas no Brasil (1899-1922). Cadernos de Pesquisa n 78. São Paulo, ago. 1991, pp. 17-26.

MAYORGA, Cláudia et al. As críticas ao gênero e a pluralização do feminino: colonialismo, racismo e política heterossexual. Revista Estudos Feministas vol. 21, no 2, Florianópolis, UFSC, 2013, pp.463484.

MATOS, Marlise. Teorias de gênero ou teorias e gênero? Se e como os estudos de gênero e feministas se transformaram em um campo novo para as ciências. Revista Estudos Feministas vol. 16, $\mathrm{n}^{\circ} 2$, Florianópolis, UFSC, ago. 2008. [http://www.scielo.br/scielo.php?script $=$ sci arttext\&pid $=$ S0104026X2008000200003\&lng=pt\&nrm =iso - acesso em: jul. 2009].

MESSNER, Michael. Boyhood organized sports, and the construction of masculinities. In: KIMEL, Michael; MESSNER, Michael. Mens, lives. New York e Toronto, MacMillan Publishing Co. e Maxwell MacMillan, 1992, pp.161-131.

PerEIRA, Sissi Aparecida Martins. O sexismo nas aulas de Educação Física: uma análise dos desenhos infantis e dos estereótipos de gênero nos jogos e brincadeiras. Tese (Doutorado em Educação Física) Programa de Pós-Graduação em Educação Física, Universidade Gama Filho, Rio de Janeiro, 2004.

RICHTER, Ana Cristina; GonÇAlves, Michelle Carreirão; VAZ, Alexandre Fernandez. Considerações sobre a presença do esporte na Educação Física Infantil: reflexões e experiências. Educar em Revista, vol. 41, 2011, pp.181-195.

RUBIN, Gayle. The traffic in women: notes on the political economy of sex. In: REITER, Rayana (Ed.). Toward an anthropology of women. New York, Monthly Review Press, 1975, pp.157-210.

SAYÃO, Deborah. Educação Física na pré-escola: da especialização disciplinar à possibilidade de trabalho pedagógico integrado. Dissertação (Mestrado) - CED/UFSC, Florianópolis, 1996.

SCOTT, Joan. Gênero: uma categoria útil de análise histórica. Educação e Realidade n²0, Porto Alegre, jul./dez., 1995, pp.71-99. 
438 educando crianças ou meninos e meninas?

THORNE, Barrie. Gender play: girls and boys in school. New Jersey, USA, Rutgers University Press, 1993.

UCHOGA, Liane Roveran. Educação física escolar e as relações de gênero: risco, confiança, organização e sociabilidades em diferentes conteúdos. Dissertação (Mestrado em Educação Física) - Faculdade de Educação Física, Universidade Estadual de Campinas, 2012.

VIANA, Aline Edwiges dos Santos. As relações de gênero em uma escola de futebol: quando o jogo é possível? Dissertação (Mestrado em Educação Física) - Faculdade de Educação Física, Universidade Estadual de Campinas, 2012.

VIANNA, Claudia; FINCO, Daniela. Meninas e meninos na Educação Infantil: uma questão de gênero e poder. Cadernos Pagu (33), Campinas, Núcleo de Estudos de Gênero-Pagu/Unicamp, 2009, pp.265-284.

WenetZ, Ileana; Stigger, Marco P.; MeYER, Dagmar E. A construção do gênero no espaço escolar. Movimento vol. 12, Porto Alegre, 2006, pp.59-80. 